for Disease Control and Prevention website. https://www.cdc. gov/hicpac/pdf/guidelines/eic_in_HCF_03.pdf. Published 2003. Accessed November 25, 2016.

4. Gangneux J-P, Bretagne S, Cordonnier C, et al. Prevention of nosocomial fungal infection: the French approach. Clin Infect Dis 2002;35:343-346.

5. Joint Accreditation Committee contacts network. European Society for Blood and Marrow Transplantation (EBMT) and the International Society for Cellular Therapy (ISCT) website. http:// www.jacie.org/directory/national-reps. Published 2016. Accessed December 6, 2016.

6. Foundation for the Accreditation of Cellular Therapy website. http:// www.factwebsite.org/. Published 2014. Accessed December 6, 2016.

7. Nosocomial invasive aspergillosis in a heart transplant patient acquired during a break in the HEPA air filtration system. Transpl Infect Dis 2004;6:50-54.

8. Poirot J-L, Gangneux J-P, Fischer A, et al. Evaluation of a new mobile system for protecting immune-suppressed patients against airborne contamination. Am J Infect Control 2007;35:460-466.

9. Bergeron V, Reboux G, Poirot JL, Laudinet N. Decreasing airborne contamination levels in high-risk hospital areas using a novel mobile air-treatment unit. Infect Control Hosp Epidemiol 2007;28:1181-1186.

10. Fréalle E, Lestrez C, Skierlak T, et al. Fungal aero-decontamination efficacy of mobile air-treatment systems. Med Mycol 2011;49:825-833.

\section{Attire as a Fomite: Proposal for a New Index Concerning Change of Attire}

To the Editor-Haun et al $^{1}$ wrote a review of the literature regarding 2 fomites found in hospitals: devices and attire. This article raises the importance of hygiene in inpatient units to prevent increasingly multidrug-resistant bacteria in hospitals all over the world, and this issue is particularly relevant to our practice. We would like to contribute our experience in a French military hospital to their findings.

In France, we have seen an increase of patients infected or colonized with MRB. For example, Arnaud et $\mathrm{al}^{2}$ showed that the incidence of extended $\beta$-lactamase-positive Enterobacteriaceae infections in French hospitals increased by $73 \%$ from 0.35 to 0.60 per 1,000 patient days $(P<.001)$ from 2009 to 2013 . Consequently, the risk of cross infection increases. ${ }^{3}$ In this context, we wanted to improve infection prevention in our hospital this past year. Because the indicator of consumption of hydro-alcoholic solution, ICSHA-2 (indicateur de consommation de solutions hydro-alcooliques number 2) is at its highest in our hospital, we focused our attention on 2 other fomites (ie, like Haun et al): devices and attire. ${ }^{4}$

We first studied the bacterial contamination of mobile phones. We obtained 80 samples from 40 phones from 40 people of all healthcare occupations: nurses, doctors, nursing aides and hospital service agents. Overall, 16 mobile phones (40\%) were contaminated (ie, $>50$ colony forming units $/ 25 \mathrm{~cm}^{2}$ ). Indicator bacteria were found on 3 phones: Staphylococcus aureus $(\mathrm{n}=2)$ and Escherichia coli $(\mathrm{n}=1)$. Mobile phones of doctors and nurses were contaminated more often than those of other healthcare workers: $65 \%$ versus $35 \%$, respectively $(P=.01)$.

In a second investigation, we controlled the implementation of standard precautions ${ }^{5}$ when a patient was hospitalized for pneumonia because of K. pneumoniae OXA48. We recognized that doctors did not change professional attire every day. Thus, we created a new hospital hygiene indicator: index of change of attire (ICA).

The goal is that each caregiver changes attire every day. This ICA is calculated using 2 variables. The first, referred to as $\mathrm{X}$, is the number of outfits washed each month in the hospital. We were able to measure this variable with the assistance of the laundry service. The second variable, referred to as $\mathrm{Y}$, is the number of monthly working days contributed by all hospital healthcare workers at our institution. We were able to measure this variable with the help of the office of human resources. We then calculated the ICA as ICA $=\mathrm{X} / \mathrm{Y}$. According to our stated goal, the ICA should be $\geq 1$.

In our hospital, ICA was $<1$; it was 0.57 for pants and 0.60 for white gowns. Thus, we sought to determine why all healthcare workers did not change attire daily. In some inpatient units, the reasons were material. For example, the number of outfits worn by doctors was insufficient. An outfit is worn for 1 day then put into the dirty laundry circuit. The dirty outfits are sent to the laundry service at an outside company. The clean garments are returned to the hospital and are distributed to the units. The entire procedure takes 2 weeks. Consequently, each doctor needs at least 12 complete outfits.

To improve the ICA, we changed the contract with the laundry company so that each healthcare worker and doctor were provided the exact number of garments according to his/her scheduled work days. We launched an information campaign regarding wearing and changing attire. The management of our hospital took part in this information campaign to emphasize its importance to all healthcare workers. Hygiene training was provided regarding awareness of the problems of changing attire and mobile phone contamination. In 6 months, we will complete a "before-and-after" study to determine the impact of these measures on our ICA and the number of cross infections in our hospital.

\section{ACKNOWLEDGMENTS}

Financial support: No financial support was provided relevant to this article.

Potential conflicts of interest: All authors report no conflicts of interest relevant to this article.

Richard Pougnet, MD; ${ }^{1}$ Laurence Pougnet, $\mathrm{MD}^{2}$

Affiliations: 1. Occupational Diseases Unit, Universitary Hospital Morvan, Brest, France; 2. Hospital Hygiene Unit, Military Hospital, ClermontTonnerre, Brest, France.

Address correspondence to Dr Richard Pougnet, 10, Rue des onze martyrs, 29200 Brest, France (richard.pougnet@live.fr). 
Infect Control Hosp Epidemiol 2017;38:629-630

(C) 2017 by The Society for Healthcare Epidemiology of America. All rights reserved. 0899-823X/2017/3805-0025. DOI: 10.1017/ice.2017.20

\section{REFERENCES}

1. Haun N, Hooper-Lane C, Safdar N. Healthcare personnel attire and devices as fomites: a systematic review. Infect Control Hosp Epidemiol 2016;37:1367-1373.

2. Arnaud I, Maugat S, Jarlier V, Astagneau P, National Early Warning, Investigation and Surveillance of HealthcareAssociated Infections Network (RAISIN)/Multidrug Resistance Study Group. Ongoing increasing temporal and geographical trends of the incidence of extended-spectrum beta-lactamaseproducing Enterobacteriaceae infections in France, 2009 to 2013. Euro Surveill 2015;19: pii $=20804$.

3. Cardoso T, Almeida M, Carratalà J, et al. Microbiology of healthcare-associated infections and the definition accuracy to predict infection by potentially drug resistant pathogens: a systematic review. BMC Infect Dis 2015;11:15-565.

4. Huskins WC, Huckabee CM, O'Grady NP, et al; STAR ${ }^{\star} I C U$ Trial Investigators. Intervention to reduce transmission of resistant bacteria in intensive care. N Engl J Med 2011;364: 1407-1418.

5. Tschudin-Sutter S, Sepulcri D, Dangel M, Schuhmacher H, Widmer AF. Compliance with the World Health Organization hand hygiene technique: a prospective observational study. Infect Control Hosp Epidemiol 2015;36:482-483.

\section{Multidrug-Resistant Organisms in the Rooms of Patients in Healthcare Facilities}

To the Editor-The study by Shams et $\mathrm{al}^{1}$ adds to the existing body of literature demonstrating the frequent environmental presence of multidrug-resistant organisms (MDROs), including Clostridium difficile, in the rooms of patients in healthcare facilities. I commend the authors for their work and wish to make a few comments.

First, it might have been helpful to analyze the data from long-term care facilities and acute-care hospitals separately, given the potential differences in infection control protocols, MDRO prevalence, patient mix, and the variable impact of infection control interventions, including environmental cleaning, on healthcare-associated infections between these 2 types of facilities. ${ }^{2,3}$ Second, it would have been useful to report the breakdown of hospital rooms by specialized units (eg, burn or intensive care units) versus general wards to help the reader determine the generalizability of the results to their specific hospital units. Third, given the varied methods of terminal cleaning of patient rooms (including the adoption of "no-touch" technologies) in response to the ongoing transmission of MDROs in healthcare facilities, ${ }^{4,5}$ further clarification of the methodology and type of cleaning products used (reported to have been recorded as stated in the Methods section) by participating facilities would have been welcome. Lastly, with $30 \%$ of rooms remaining culture positive for MDROs after terminal cleaning - with their attendant risk of transmission to the new occupants ${ }^{6}$ - the results of the study by Shams et al support those of prior works demonstrating similarly high rates of MDRO-positive rooms despite seemingly adequate terminal cleaning. ${ }^{7-9}$ Although, as stated by the authors, the relationship between the levels of microbial contamination in the environment and patient acquisition of MDROs remains unclear, one could argue that under the right circumstances in a susceptible host (eg, immunosuppressed or with open wounds), no level of environmental contamination with MDROs in terminally cleaned rooms may be considered safe, and that more effort should be directed now toward devising safe and cost-effective means of eliminating them from the surfaces of all newly vacated patient rooms.

\section{ACKNOWLEDGMENTS}

The content is solely the responsibility of the author and does not necessarily represent the official views of Harvard Catalyst, Harvard University, its affiliate academic healthcare centers, or its corporate contributors.

Financial support: No financial support was provided relevant to this article.

Potential conflicts of interest: The author reports no conflicts of interest relevant to this article.

\section{Farrin A. Manian, MD, MPH}

Affiliations: Department of Medicine, Massachusetts General Hospital, Harvard Medical School, Boston, Massachusetts.

Address correspondence to Farrin A. Manian, MD, MPH, Department of Medicine, Mass General Hospital, 50 Staniford St, Suite 503B, Boston, MA 02114 (Fmanian@mgh.harvard.edu).

Infect Control Hosp Epidemiol 2017;38:630-631

(C) 2017 by The Society for Healthcare Epidemiology of America. All rights reserved. 0899-823X/2017/3805-0026. DOI: 10.1017/ice.2017.23

\section{REFERENCES}

1. Shams AM, Rose LJ, Edwards JR, et al. Assessment of the overall and multidrug-resistant organism bioburden on environmental surfaces in healthcare facilities. Infect Control Hosp Epidemiol 2017;37:1426-1432.

2. Nicolle LE. Infection control in long-term care facilities. Clin Infect Dis 2000;31:752-756.

3. Makris AT, Louise M, Gaber DJ, Richter A, Rubino JR. Effect of a comprehensive infection control program on the incidence of infections in long-term facilities. Am J Infect Control 2000; 28:3-7.

4. Rutala WA, Weber DJ. Disinfectants used for environmental disinfection and new room decontamination technology. Am J Infect Control 2013;41:S36-S41.

5. Manian FA, Griesnauer S, Bryant A. Implementation of hospitalwide enhanced terminal cleaning of targeted patient rooms and its impact on Clostridium difficile infection rates. Am J Infect Control 2013;41:537-541.

6. Otter JA, Yezli S, Salkeld JAG, French GL. Evidence that contaminated surfaces contribute to the transmission of 